\title{
An unusual case of a misplaced left internal jugular vein catheter
}

\author{
Sunil Rangarajan, Sunad Rangarajan, Lindsey Smith Hinton
}

\begin{abstract}
Introduction: Most often, cannulation of the right internal jugular vein (IJV) is preferred over the left IJV. However, in situations where the right IJV cannot be utilized for accessing the central circulation, as in our case, the left IJV is used. Cannulation of left IJV has additional risks due to the anatomical variations. Despite the use of ultrasound guidance, anatomical variations and tortuous course of the left IJV make cannulation of the left IJV more prone to the failure of cannulation or malposition of the cannula leading to catastrophic complications. Case Report: A 63-year-old female with multiple comorbidities presented with progressive shortness of breath and mild respiratory distress due to bibasilar pneumonia. Despite aggressive management of her pneumonia, she continued to deteriorate and became increasingly hypoxemic, hypotensive with abnormal renal functions necessitating medical intensive care treatment and continuous hemodialysis. As she had a chemo-port in her right subclavian vein, it was determined to avoid insertion of the dialysis catheter in her right IJV. An attempt was made to insert the catheter
\end{abstract}

Sunil Rangarajan ${ }^{1}$, Sunad Rangarajan², Lindsey Smith Hinton $^{3}$

Affiliations: ${ }^{1} \mathrm{MBBS}$, Postdoctoral Scholar, University of Alabama at Birmingham, Birmingham, AL; ${ }^{2} \mathrm{MD}$, Fellow, Pulmonary and Critical Care, University of Alabama at Birmingham, Birmingham, AL; ${ }^{3} \mathrm{MD}$, Resident, Internal Medicine, University of Alabama at Birmingham, Birmingham, AL.

Corresponding Author: Sunil Rangarajan, Postdoctoral Scholar, University of Alabama at Birmingham, 1720, 2nd Avenue South, LHRB 452, Birmingham, Alabama - 35294; Ph: 205-934-5783; Fax: 205-975-6288; Email : sunilr@uab. edu

Received: 27 October 2012

Accepted: 18 February 2012

Published: 01 October 2013 in her left IJV under ultrasound guidance. The catheter was inserted without any perceived resistance. Blood withdrawn from the ports was however, bright red, and gas analysis revealed arterial blood values. A bed side $X$-ray revealed that the catheter was in the heart. Conclusion: This is the first reported case where the tip of the cannula was in the left atrium. Despite the use of ultrasound guidance, the anatomical variations and the tortuous course of the left internal jugular vein make its cannulation more prone to failure or malposition of the cannula leading sometimes to catastrophic complications. This case reinforces studies which have shown that even with ultrasound guidance, left internal jugular vein cannulation is fraught with higher risk of complications.

Keywords: Central vein cannulation, Internal jugular vein (IJV)

$* * * * * * * * *$

Rangarajan S, Rangarajan S, Hinton LS. An unusual case of a misplaced left internal jugular vein catheter. International Journal of Case Reports and Images 2013;4(10):567-570.

$* * * * * * * * *$

doi:10.5348/ijcri-2013-10-381-CR-10

\section{INTRODUCTION}

Internal jugular veins (IJVs) are often used for an access into the central circulation. The right IJV provides a straight path to the heart. The anatomical variations that are often present in the left IJV pose a challenge in accessing the central circulation. There are very few prospective studies to compare the safety of inserting the catheter into the right against the left IJV [1]. We 
present a case of a misplaced catheter, which perforated the left IJV into the mediastinum, the bifurcation of the pulmonary artery, and the left atrium.

\section{CASE REPORT}

A 63-year-old female with history of diabetes mellitus, hypertension, atrial fibrillation, colon cancer managed by surgical resection and chemotherapy presented with progressive shortness of breath. She had recently undergone cholecystectomy and then splenectomy elsewhere for pancytopenia which had subsequently been attributed to myelodysplastic syndrome. Clinical examination revealed a middle aged woman in mild respiratory distress with significant systemic exam findings being scattered crackles and irregular heart rate. Chest roentgenogram suggested bibasilar pneumonia. As she became increasingly hypoxemic, hypotensive and short of breath, she was admitted to the medical intensive care unit for the management of septic shock and respiratory failure from acute respiratory distress syndrome due to pneumonia. Despite aggressive treatment she continued to deteriorate and her renal function worsened, necessitating continuous hemodialysis. As she had a chemo-port in her right subclavian vein, it was determined to avoid insertion of the dialysis catheter in her right internal jugular vein (IJV). An attempt was made to insert the catheter by Seldinger technique in her left IJV under ultrasound guidance. The catheter was inserted without any perceived resistance. Blood that returned from the ports was however, bright red, and gas analysis revealed arterial blood values. The screening chest X-ray showed a possible malposition of the catheter. Further, a computed tomography (CT) scan scout image (Figure 1) showed an aberrant downward course of the catheter on the left side of the mediastinum with its tip in the cardiac area. Further imaging revealed the catheter to have punctured the left IJV (Figure 2A), into the mediastinum lateral to the aortic arch missing it narrowly, the main pulmonary artery at its bifurcation (Figure 2B) and the left atrium of the heart (Figure 3). The patient was unstable for sternotomy to remove the catheter. Her overall condition worsened further and as per family's wishes, care was withdrawn and she expired.

\section{DISCUSSION}

Most often, cannulation of the right IJV is preferred over the left IJV. However, in situations where the right IJV cannot be utilized for accessing the central circulation as in our case, the left IJV is used. The anatomy of the left IJV makes a central venous line pass through two near90-degree turns, the first at the junction of the left IJV and the left subclavian vein, and the second at the junction of the left brachiocephalic vein and the superior vena cava.

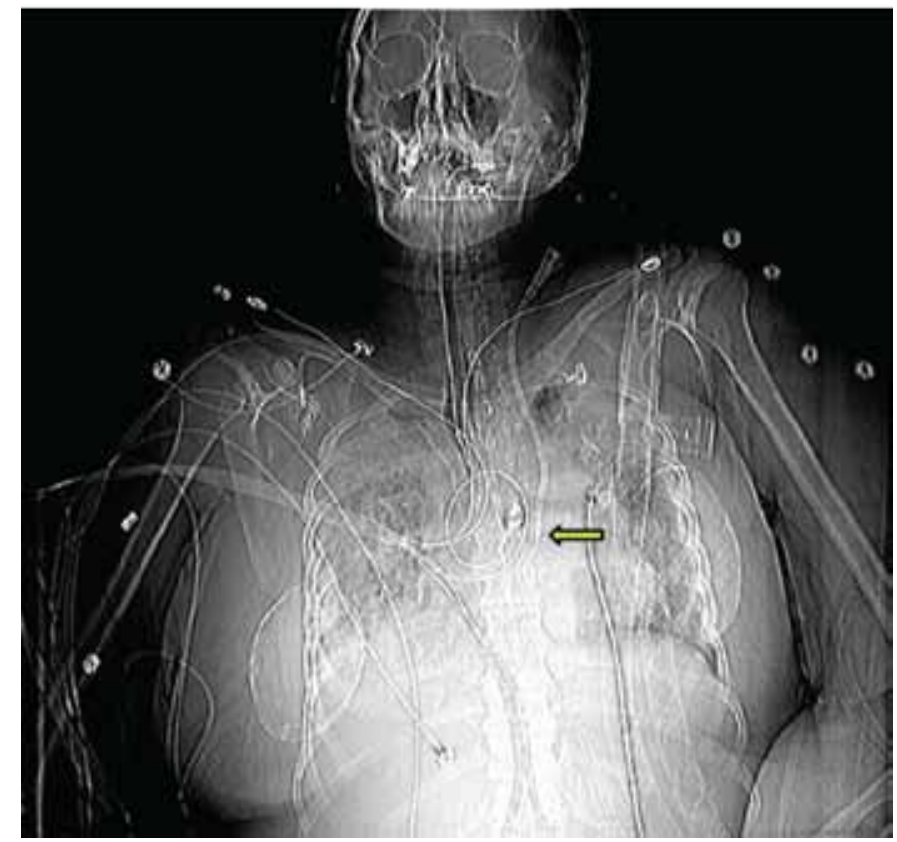

Figure 1: Scout image showing aberrant downward course of the catheter on the left side of the mediastinum with its tip in the left atrium (yellow arrow).

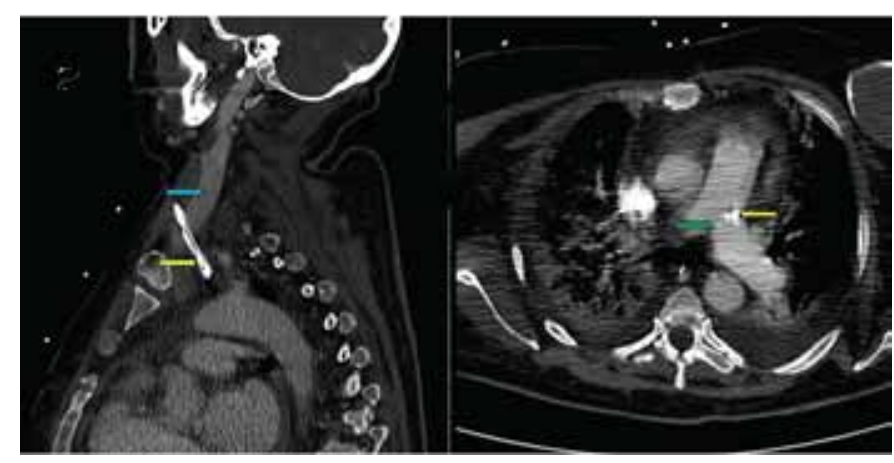

Figure 2: (A) Catheter (yellow arrow) seen puncturing the left internal jugular vein (blue arrow) into the mediastinum, (B) Catheter (yellow arrow) seen inside the pulmonary artery at its bifurcation (green arrow).

In addition, the left IJV has several anatomical variations. Occasionally, people may have a normal variant of the left IJV that drains into the left superior vena cava with or without a bridging vein. The overlap of the IJV over the carotid artery is more on the left when the head rotation is greater than 30 degrees $[2,3]$. One should be cognizant of this difference while inserting a catheter into the left IJV. It is observed that in more than one-third of the normal population, left IJV is half the size of the right IJV making the procedure more difficult $[4,5]$.

Cannulation of the IJV can be done either using the landmark approach (using point of needle insertion as the apex of the triangle formed by the two heads of the sternocleidomastoid muscle with the base as the clavicle) or the ultrasound guided approach. The risk of a serious 


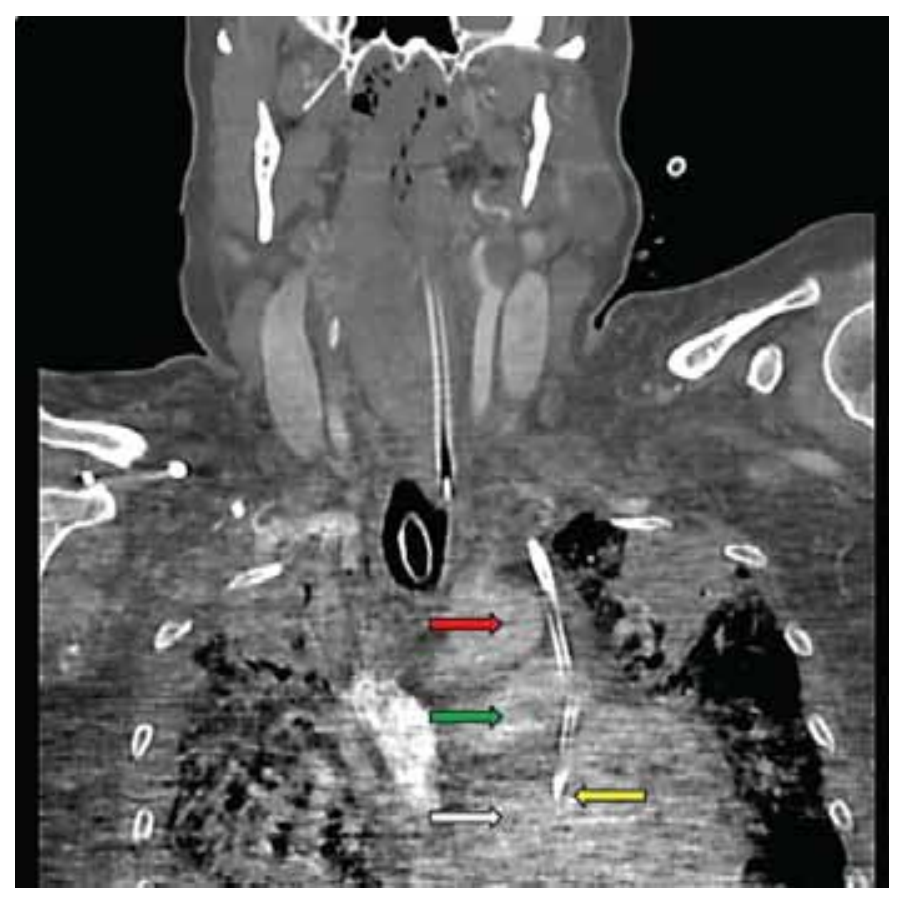

Figure 3: Computed tomography of the chest: Catheter (yellow arrow) noted millimeters from puncturing the aorta (red arrow), traversing the pulmonary artery (green arrow), and entering the left atrium (white arrow).

complication while performing the landmark approach is much higher. In a prospective study, the most dangerous complications which occurred in patients who were catheterized using the landmark approach included puncture of the carotid artery occurred in $10.6 \%$, hematoma in $8.4 \%$, hemothorax in $1.7 \%$, pneumothorax in $2.4 \%$ and central venous catheter-associated blood stream infection in 16\% [6]. The success rate of inserting the cannula was higher in the ultrasound guided approach than in the landmark approach. Muralidhar reported a $19 \%$ incidence of failure or cannula malposition while attempting on the left IJV compared to $3 \%$ with the right IJV, using the landmark technique [7].

In the present day, the use of ultrasound guidance has become ubiquitous while inserting a cannula into the IJV. Despite the use of ultrasound guidance, the above mentioned factors make cannulation of the left IJV more prone to failure of cannulation or malposition of the cannula leading to catastrophic complications [8-10]. There are a handful of cases reported in the medical literature where the catheterization of the left IJV has caused a cardiac tamponade $[11,12]$. This is the first reported case where the cannula has finally landed inside the left atrium without cardiac tamponade.

\section{CONCLUSION}

This case reinforces studies which have shown that even with ultrasound guidance, left internal jugular vein cannulation is fraught with higher risk of complications than on the right side. In situations where the right internal jugular vein cannot be catheterized, extra caution has to be taken while attempting to obtain venous access through the left internal jugular vein.

$$
* * * * * * * * *
$$

\section{Author Contributions}

Sunil Rangarajan - Conception and design, Acquisition of data, Drafting of the article, critical revision of the article, Final approval of the version to be published Sunad Rangarajan - Conception and design, acquisition of data, Drafting of the article, Critical revision of the article, Final approval of the version to be published Lindsey Smith Hinton - Acquisition of data, Drafting of the article, Final approval of the version to be published

\section{Guarantor}

The corresponding author is the guarantor of submission.

\section{Conflict of Interest}

Authors declare no conflict of interest.

\section{Copyright}

(C) Sunil Rangarajan et al. 2013; This article is distributed under the terms of Creative Commons attribution 3.0 License which permits unrestricted use, distribution and reproduction in any means provided the original authors and original publisher are properly credited. (Please see www.ijcasereportsandimages.com/copyright-policy.php for more information.)

\section{REFERENCES}

1. Sulek CA, Blas ML, Lobato EB. A randomized study of left versus right internal jugular vein cannulation in adults. J Clin Anesth 2000 Mar;12(2):142-5.

2. Lorchirachoonkul $\mathrm{T}$, Ti LK, Manohara $\mathrm{S}$, et al. Anatomical variations of the internal jugular vein: implications for successful cannulation and risk of carotid artery puncture. Singapore Med J 2012 May;53(5):325-8.

3. Lieberman JA, Williams KA, Rosenberg AL. Optimal head rotation for internal jugular vein cannulation when relying on external landmarks. Anesth Analg 2004 Oct;99(4):982-8.

4. McGee WT, Mallory DL. Cannulation of the internal and external jugular veins. Prob Crit Care 1988;2:217-41.

5. Lobato EB, Sulek CA, Moody RL, Morey TE. Cross-sectional area of the right and left internal jugular veins. J Cardiothorac Vasc Anesth 1999 Apr;13(2):136-8.

6. Karakitsos D, Labropoulos N, De Groot E, et al. Real-time ultrasound-guided catheterisation of the internal jugular vein: a prospective comparison with the landmark technique in critical care patients. Crit Care 2006;10(6):R162. 
7. Muralidhar K. Left internal versus right internal jugular vein access to central venous circulation using the Seldinger technique. J Cardiothorac Vasc Anesth 1995 Feb;9(1):115-6.

8. Lee EK. An unexpected left hydrothorax after left internal jugular venous catheterisation for total parental nutrition and antibiotics. Ann Acad Med Singapore 2006 Oct;35(10):742-4.

9. Khajavi MR, Sedighi M. Malposition of central venous catheter in the left internal jugular vein--a case report. Middle East J Anesthesiol 2006 Oct;18(6):1157-60.
10. Ghosh S, Dewan H, Bhattacharyya S. A rare malposition of the thoracic venous catheter introduced via the left internal jugular vein. Indian $J$ Crit Care Med 2008 Oct;12(4):201-3.

11. van Haeften TW, van Pampus EC, Boot H, Strack van Schijndel RJ, Thijs LG. Cardiac tamponade from misplaced central venous line in pericardiophrenic vein. Arch Intern Med $1988 \mathrm{Jul} ; 148(7): 1649-50$.

12. Al-Azawi O, Shehab $\mathrm{R}$, Ababneh MO. Cardiac temponade following left internal jugular venous catheterization--a case report. Middle East $J$ Anesthesiol 2006 Oct;18(6):1161-4.
Access full text article on other devices

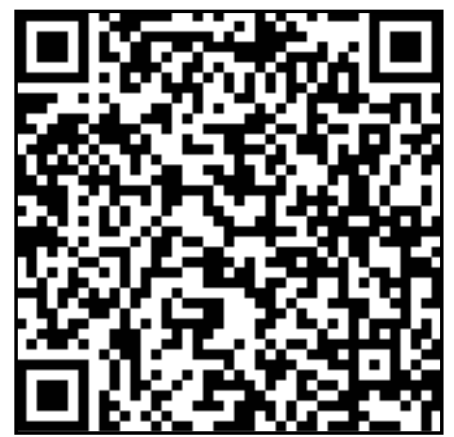

Access PDF of article on other devices

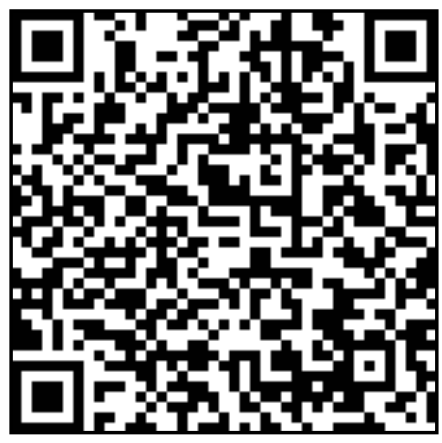

